\title{
Acinetobacter baylyi regulates type IV pilus synthesis by employing two extension motors and a motor protein inhibitor
}

\author{
Courtney K. Ellison ${ }^{1,2^{*}}$, Triana N. Dalia ${ }^{3}$, Catherine A. Klancher ${ }^{3}$, Joshua W. Shaevitz ${ }^{1^{*}}$, Zemer Gitai ${ }^{2^{*}}$, and \\ Ankur B. Dalia ${ }^{3^{*}}$ \\ 1. Lewis-Sigler Institute for Integrative Genomics, Princeton University, Princeton, NJ \\ 2. Department of Molecular Biology, Princeton University, Princeton, NJ \\ 3. Department of Biology, Indiana University, Bloomington, IN \\ *Correspondence to: c.ellison@princeton.edu, shaevitz@princeton.edu, zgitai@princeton.edu, ankdalia@indiana.edu
}

\begin{abstract}
Bacteria use extracellular appendages called type IV pili (T4P) for diverse behaviors including DNA uptake, surface sensing, virulence, protein secretion, and twitching motility ${ }^{1}$. Dynamic extension and retraction of T4P is essential for their function, yet little is known about the mechanisms controlling these dynamics or the extent to which their regulation is conserved across bacterial species. Here, we develop Acinetobacter baylyi as a new model to study T4P by employing a recently developed pilus labeling method ${ }^{2,3}$. Our findings overturn the current dogma that T4P extension occurs through the action of a single, highly conserved motor, PilB, by showing that T4P synthesis in $A$. baylyi is dependent on an additional, phylogenetically distinct motor, TfpB. Furthermore, we uncover an inhibitor of T4P extension that specifically binds to and inhibits PilB but not TfpB. These results expand our understanding of T4P regulation and highlight how inhibitors might be exploited to inhibit T4P synthesis.
\end{abstract}

\section{Introduction}

T4P are thin, proteinaceous appendages that are broadly distributed throughout bacteria and archaea ${ }^{4}$. T4P are composed primarily of major pilin protein subunits that are polymerized or depolymerized through the activity of ATPases to mediate fiber extension and retraction, respectively ${ }^{5}$. T4P are subdivided into subcategories (generally $\mathrm{T} 4 \mathrm{aP}, \mathrm{T} 4 \mathrm{bP}$, and $\mathrm{T} 4 \mathrm{cP}$ ) based on protein homology and pilus function, with T4aP being the bestcharacterized. In the T4aP systems found in Gram-negative organisms, polymerization and depolymerization of pilins occurs through interactions of the extension ATPase PilB or retraction ATPase PilT with the integral inner membrane platform protein PilC (Supplemental figure 1a). The growing fiber spans an alignment complex from the inner membrane through the periplasm composed of PilNOP to exit through the PilQ outer membrane secretin pore. Dynamic cycles of T4P extension and retraction are critical for the diverse processes that these structures mediate including twitching motility $^{6}$, surface sensing ${ }^{2,7}$, virulence ${ }^{8,9}$, and DNA uptake $^{10,11}$.

Acinetobacter species like $A$. baumannii and $A$. nosocomialis have emerged to become an urgent medical threat due to their prevalence in hospital-acquired infections and their capacity to acquire antibiotic resistance genes; a process that is achieved in part by natural transformation through T4aP-mediated DNA uptake ${ }^{12,13}$. Acinetobacter baylyi is the most naturally transformable species reported to date ${ }^{14}$, with up to $50 \%$ of cells undergoing natural transformation in laboratory conditions, making it an ideal candidate to study T4P-mediated DNA uptake and natural transformation.

\section{Results}

To study $A$. baylyi T4P, we applied a recently-developed labeling method ${ }^{2,3}$ by targeting the major pilin, ComP, for cysteine substitution and subsequent labeling with thiolreactive maleimide dyes. Maleimide-labeling of the functional comP $P^{\top 129 C}$ strain (Supplemental figure $1 \mathrm{~b}, 1 \mathrm{c}$ ) revealed external T4P filaments as seen in other species using this method ${ }^{3}$. T4P in $A$. baylyi appear much shorter than those found in other species like $V$. cholerae, and they localize close together in a line along the long axis of the cell (Supplemental figure 1c). Incubation of cells with fluorescently-labeled DNA resulted in co-localization of DNA with T4P, which is consistent with the essential role of T4P-DNA binding during natural transformation in Vibrio cholerae $^{11}$ (Figure 1a). We reasoned that natural transformation could be used to screen for other factors that regulate T4P synthesis in $A$. baylyi. To that end, we performed a high throughput transposon-sequencing screen $(T n-s e q)^{15}$ to identify genes required for natural transformation. In this screen, loss of known T4P-related genes resulted in negative selection, indicating that they were critical for natural transformation as expected (Figure 1b). To validate our Tn-seq results, we made in-frame deletions of representative genes from each T4P-encoding operon, as well as genes known to be essential for natural transformation that act downstream of T4P. Mutations in the T4P platform protein gene pilC, the pilus regulatory gene pilY1, the outer membrane secretin gene pilQ and the retraction ATPase gene pilT all showed a marked reduction in natural transformation, with most mutants exhibiting transformation rates below our limit of detection (Figure 1c). T4P-labeling of pilC, pilY1, and pilQ mutants revealed no visible T4P fibers (Figure 1d). Mutations in genes that act downstream of T4P, including the periplasmic DNA-binding protein gene comEA, the inner membrane DNA-transporter protein gene comEC, and the DNA-recombination helicase gene comM likewise resulted in a reduction in transformation frequency, however, these strains still produced T4P fibers as expected (Figure 1c, d). 


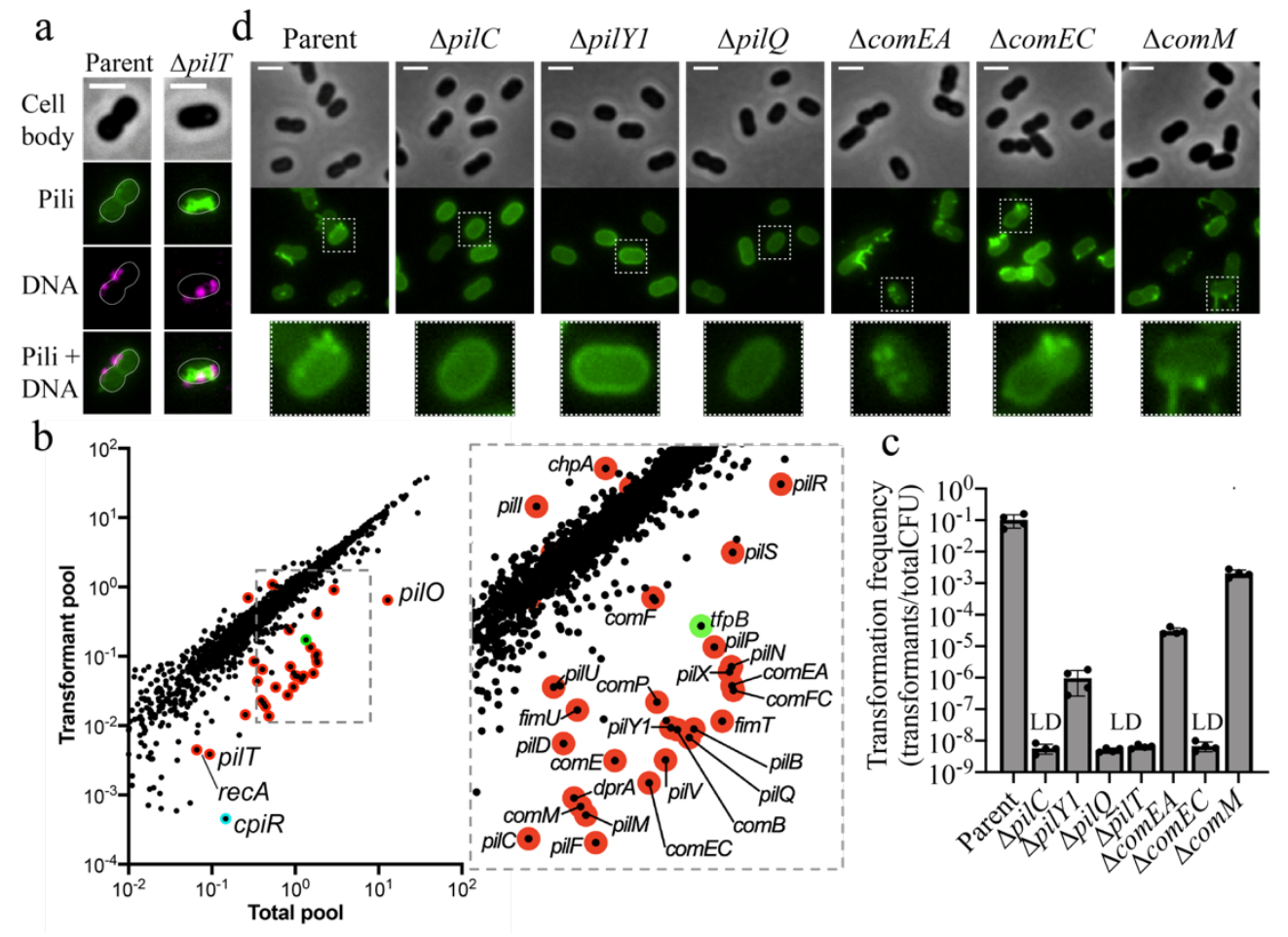

Figure 1. Tn-seq reveals factors important for natural transformation and T4P synthesis. (a) Representative images of cells with AF488-mal labeled pili incubated with fluorescently-labeled DNA. (b) Visual representation of Tn-seq screen showing the relative abundance of each gene in the "total pool" of transposon mutants compared to the "transformant pool" recovered after natural transformation. Known T4P structural/regulatory genes are outlined in red. $t f p B$ is outlined in green, and $c p i R$ is outlined in cyan. (c) Natural transformation assays of indicated strains. Each data point represents a biological replicate and bar graphs indicate the mean $\pm S D$. LD, limit of detection. (d) Representative images of strains from natural transformation assays shown in $\mathbf{c}$ labeled with AF488-mal. Zoomed-in images of representative single cells from each strain are outlined in dashed boxes and shown below. Scale bars, $2 \mu \mathrm{m}$.

We next sought to determine whether any of the previously uncharacterized genes from our Tn-seq screen reduced natural transformation in $A$. baylyi by affecting T4P synthesis. Tn-seq revealed that mutations in pilB, the canonical extension ATPase gene that is typically cotranscribed with pilC and the pre-pilin peptidase, pilD, resulted in reduced natural transformation (Figure $1 b$ ). We also found an additional pilB homologue that likewise exhibited lower rates of transformation (Figure 1b). We named this new PilB homologue TfpB for "type four pilus PilB-like protein" because although it has homology to PilB, it does not exhibit the same gene synteny as pilB genes that are typically co-transcribed with their cognate inner membrane platform gene pilC. Surprisingly, deletion of the canonical pilB did not ablate transformation as would be expected based on homology to other T4P ${ }^{10}$ (Figure 2a). Mutation of $t f p B$ reduced transformation rates to a level that was similar to the pilB mutant; however, natural transformation was undetectable in the pilB $t f p B$ double mutant (Figure 2a).

Deletion of pilT prevents T4P retraction ${ }^{16}$ and may thus reveal more subtle effects on pilus extension. T4P labeling in pilB, $t f p B$, and pilB tfpB mutants revealed that all three mutants were defective in T4P synthesis while pilT was intact (Figure 2c). In a pilT deletion background, pilB mutant populations had similar numbers of cells producing
T4P compared to the $\Delta$ pilT parent while, surprisingly, $t f p B$ mutants were highly defective in T4P synthesis (Figure $2 \mathrm{~b}$, c). The pilB tfpB pilT triple mutant produced no detectable T4P fibers (Figure $2 b, c$ ). Together, these results indicate that both PilB and TfpB are essential for efficient T4P extension in $A$. baylyi, with TfpB playing the dominant role.

Phylogenetic analysis of extension ATPase homologues found among Gammaproteobacteria ${ }^{4,17}$, which include members of the PilT/VirB11 family of secretion ATPases, revealed that TfpB clusters with a group of proteins that are phylogenetically distinct from the canonical PilB ATPase (Figure 2d, Supplemental figure 2). PilB and TfpB proteins are as divergent from one another as PilB and the type II secretion system proteins $\mathrm{XcpR} / \mathrm{GspE}$, or PilB and the MshE motors that drive mannose-sensitive haemagglutinin (MSHA) pilus synthesis, suggesting that TfpB evolved as a functionally divergent class of proteins that is distinct from canonical PilB extension motors. TfpB is highly conserved in other Acinetobacter species (Figure 2d, Supplemental figure 2), implying that use of multiple extension motors may be prevalent in the Acinetobacter clade. These results suggest that proteins that cluster with TfpB may play similar functions in other bacterial species and that multiple extension ATPases may be a common feature of diverse T4P. 


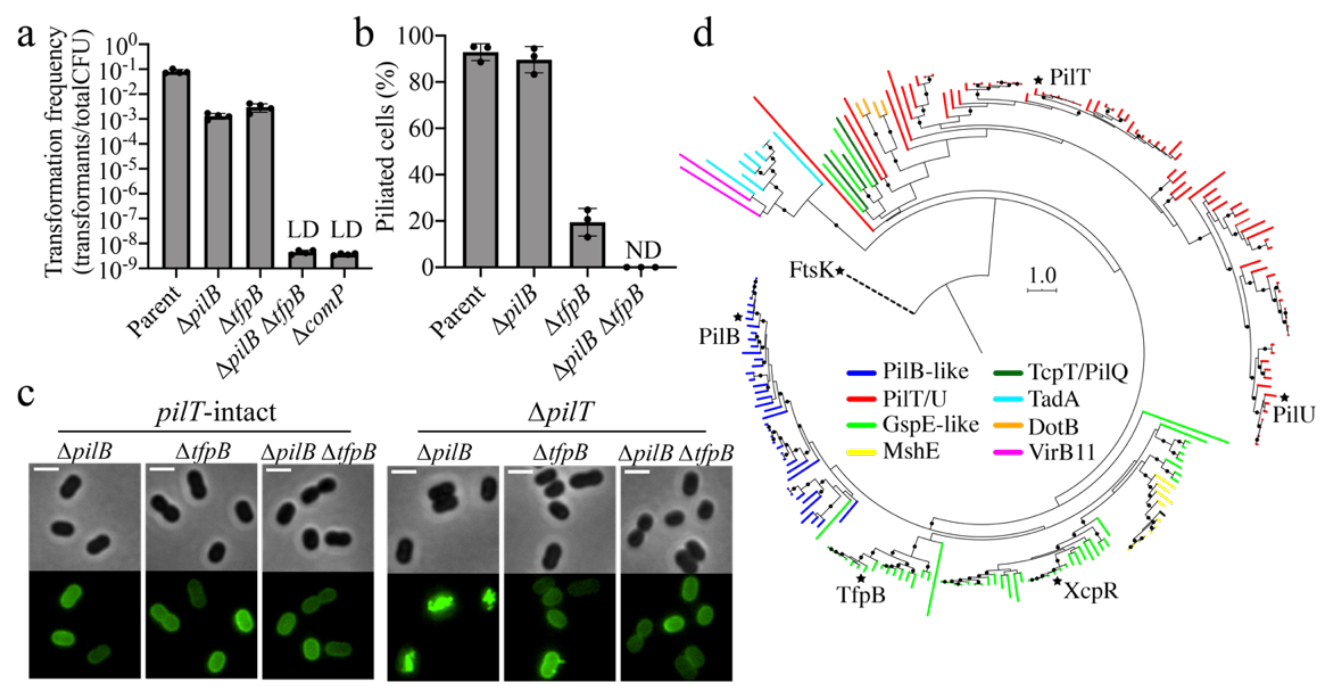

Figure 2. TfpB is a phylogenetically distinct PilB homologue that is required for efficient T4P extension in A. baylyi. (a) Natural transformation assays of indicated strains. Each data point represents a biological replicate and bar graphs indicate the mean \pm SD. LD, limit of detection. (b) Percent of piliated cells in pilT mutant populations of indicated strains. Each data point represents an independent, biological replicate and bar graphs indicate the mean \pm SD. For each biological replicate, a minimum of 70 total cells were assessed. ND, no pili detected. (c) Representative images of indicated strains labeled with AF488-mal with background fluorescence subtracted. Scale bars, $2 \mu \mathrm{m}$. (d) A rooted phylogeny of TfpB homologues found among Gammaproteobacteria. Branches are colored according to protein annotations in IMG, and nodes with bootstrap values greater than or equal to $70 \%$ are indicated by black circles. Black stars are at the tips of branches representing $A$. baylyi proteins with indicated protein names.

In addition to revealing the importance of $\mathrm{TfpB}$ in T4P synthesis, our Tn-seq results also uncovered an uncharacterized transcriptional regulator belonging to the XRE-family of transcriptional repressors that is critical for natural transformation (Figure 1b, Figure 3a). Deletion of this regulator, named cpiR for competence pilus inhibition repressor, resulted in a 100-fold reduction in transformation (Figure 3b). We hypothesized that CpiR repressed a factor that inhibits natural transformation. Transcriptional repressors are often transcribed immediately adjacent to the genes they repress. We thus deleted the upstream gene, named cpiA for competence pilus inhibition actuator (Figure $3 a$ ), and found that transformation frequency was restored in the cpiR cpiA double mutant background (Figure $3 b)$. Expression of cpiA under the control of an IPTGinducible promoter $\left(\mathrm{P}_{t a c}\right)$ was sufficient to reduce transformation frequency even in the presence of cpiR, further suggesting that CpiR represses cpiA transcription. Furthermore, we found that CpiR was sufficient to repress the cpiA promoter (using a $\mathrm{P}_{c p i A}$-GFP reporter) in the
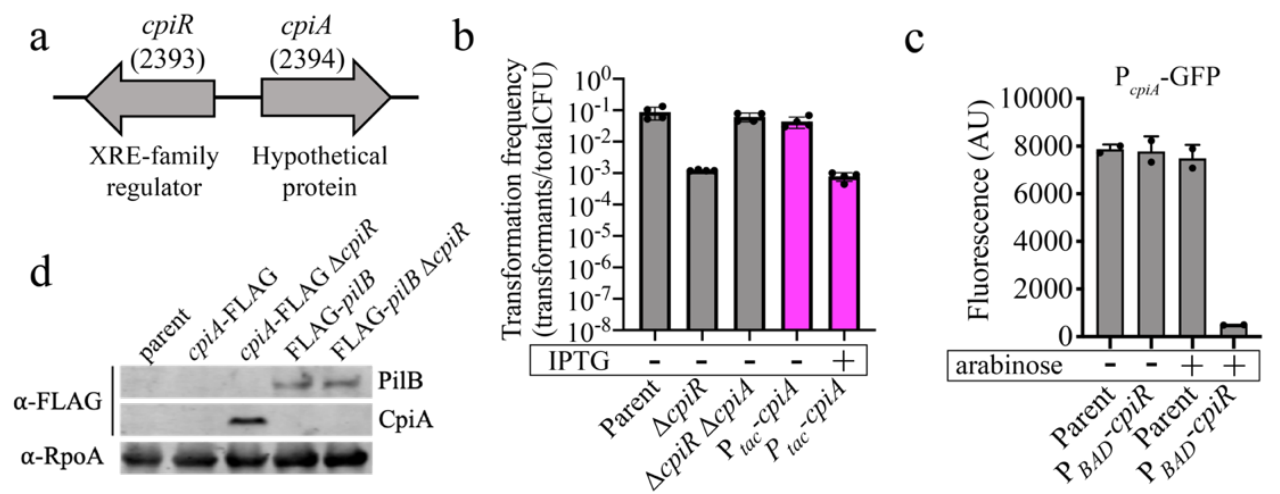

Figure 3. Natural transformation is regulated by the inhibitor protein, CpiA, whose expression is controlled by the transcriptional repressor, CpiR. (a) Schematic of cpiRA locus organization. Numbers in parentheses are ACIAD numbers associated with each gene. (b) Natural transformation assays of the indicated strains performed with or without $100 \mu \mathrm{MM}$ IPTG added as indicated. Each data point represents a biological replicate and bar graphs indicate the mean \pm SD. Pink bars denote a strain where cpiA is expressed at an ectopic location under the control of an IPTG-inducible promoter. (c) Fluorescence intensity of $V$. cholerae strains harboring a $\mathrm{P}_{c p i A}-\mathrm{GFP}$ reporter and a $\mathrm{P}_{B A D}-C p i R$ ectopic expression construct as indicated when grown with or without $0.2 \%$ arabinose as indicated. Each data point represents a biological replicate and bar graphs indicate the mean \pm SD. (d) Western blot showing CpiA-FLAG production in the indicated strains and PilB levels when CpiA is expressed. RpoA was detected as a loading control. 
$\mathrm{a}$
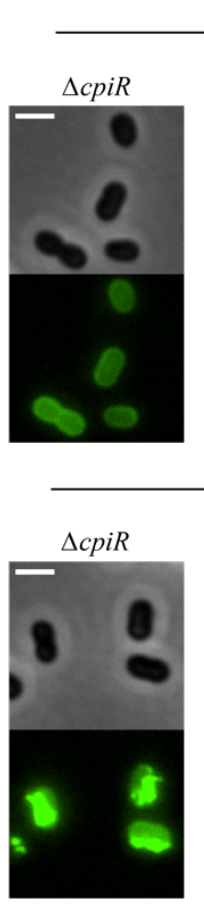

b

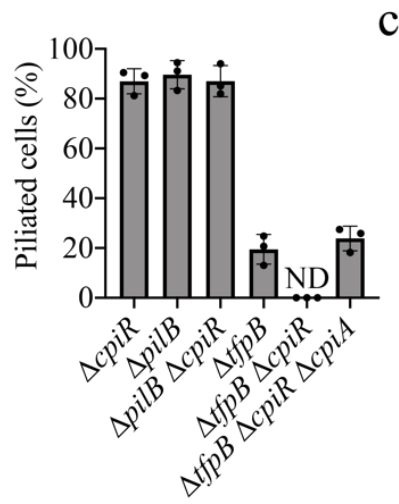

$\mathrm{c}$

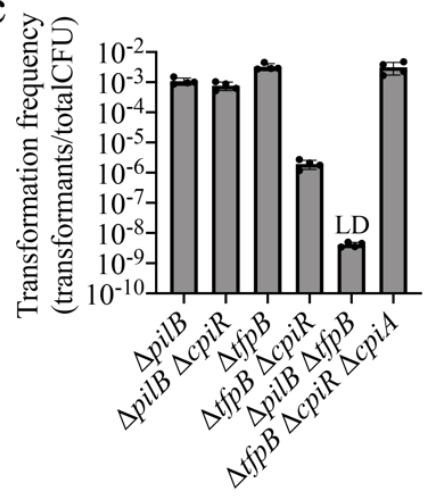

heterologous host Vibrio cholerae, which suggests that $\mathrm{CpiR}$ is a direct repressor of $\mathrm{P}_{\text {cpiA }}$ (Figure 3c). Finally, we found that CpiA protein is only produced in a cpiR mutant (Figure 3d). These results demonstrate that under lab conditions, CpiR represses cpiA transcription to allow for high rates of natural transformation; however, in the absence of CpiR, CpiA is produced and natural transformation is inhibited $\sim 100$-fold.

CpiA lacks primary sequence or structural homology to any proteins or domains of known function ${ }^{18,19}$, so we next sought to determine the mechanism of transformation inhibition by CpiA. Labeling of T4P in a cpiR mutant (i.e. when CpiA is expressed) revealed that cells were deficient in T4P synthesis (Figure 4a). This defect was dependent on cpiA because piliation was restored in the cpiR cpiA double mutant (Figure 4a). Deletion of pilT restored T4P synthesis in the cpiR mutant (i.e. the cpiR pilT double mutant) (Figure 4a, b). This phenotype was reminiscent of the restoration of piliation observed in the pilB pilT double mutant, so we hypothesized that CpiA may regulate natural transformation by inhibiting PilB.
To test if CpiA functions by inhibiting PilB, we made pilB cpiR and tfpB cpiR double mutants. T4P synthesis was unaffected in pilB cpiR pilT (where TfpB is the sole extension ATPase present), while no T4P were detected in tfpB cpiR pilT (where PilB is the sole extension ATPase present) (Figure $4 a, b)$. The defect in T4P synthesis in the tfpB cpiR pilT strain was restored when cpiA was deleted in this background, demonstrating that CpiA acts as a PilB inhibitor to control natural transformation (Figure $4 a, b)$. Transformation frequency assays corroborated these results by demonstrating that deletion of cpiR only inhibited transformation in the $t f p B$ mutant background (where PilB is the sole extension ATPase) and not the pilB mutant background (where TfpB is the sole extension ATPase) (Figure 4c). Immunoblotting revealed that CpiA does not affect PilB production or stability (Figure $3 \mathrm{~d}$ ), and we thus hypothesized that CpiA may interact with PilB to disrupt its function. Coimmunoprecipitation experiments with functional fusion proteins (Supplemental figure 3) revealed that $\mathrm{CpiA}$ and PilB interact with each other, and that their interaction is not dependent on the pilus machinery proteins PilMNOPQ (Figure 4d and Supplemental figure 4), ruling 
out indirect binding of $\mathrm{CpiA}$ to PilB through other machinery components required for T4P synthesis. CpiA and TfpB do not interact (Supplemental figure 4), consistent with our genetic evidence that CpiA specifically inhibits PilB and not TfpB (Figure 4a-c). Together, these data suggest that CpiA directly binds to and inhibits PilB.

\section{Discussion}

Environmental conditions play an integral role in regulating how bacteria respond to and interact with their surroundings. The mechanisms of T4P synthesis regulation identified here likely reflect how environmental conditions influence bacterial physiology. The acquisition of the additional extension motor TfpB and the PilB-specific inhibitory protein CpiA likely resulted from a need to modulate T4P extension under different environmental conditions. Bacteria generally limit T4P synthesis to environments where they provide a selective advantage. For example, in V. cholerae, the production of competence $\mathrm{T} 4 \mathrm{aP}$ requires chitin and quorum sensing ${ }^{20}$, which are environmental conditions that cells experience when they are likely to encounter other bacterial cells for horizontal gene transfer; while the toxin-coregulated T4bP (TCP) required for intestinal colonization are produced in response to host-specific cues ${ }^{21}$. In $A$. baylyi, both PilB and TfpB are required for T4P extension and, consequently, efficient natural transformation. While CpiA is not expressed under laboratory conditions (due to CpiR repression), it is possible that different environmental conditions derepress $c p i A$ to decrease pilus activity.

Secretion ATPases like PilB belong to a broadly distributed class of proteins that play essential roles in diverse microbial behaviors, yet there are few known inhibitors of these proteins. The ones that are characterized are encoded by phages that use T4P to infect cells, and it is speculated that PilB inhibition by these proteins prevents superinfection by other T4P-dependent phages ${ }^{22,23}$. In Acinetobacter baylyi, cpiA is encoded on the chromosome. Thus, it is tempting to speculate that CpiA was acquired after phage infection of an ancestral strain and co-opted for regulation of T4P activity. A better understanding of secretion ATPase function and the evolution of mechanisms by which they can be inhibited may enable the development of tools to control their activity. Precise control of T4P synthesis may provide a means to manipulate behaviors that require T4P like biofilm formation, virulence, and natural transformation, which are clinically relevant in diverse pathogens.

\section{Methods}

\section{Bacterial strains and culture conditions}

Acinetobacter baylyi strain ADP1 was used throughout this study. For a list of strains used throughout, see Supplemental Table 1. A. baylyi cultures were grown at $30^{\circ} \mathrm{C}$ in Miller lysogeny broth (LB) medium and on agar supplemented with kanamycin (50 $\mu \mathrm{g} / \mathrm{mL})$, spectinomycin $(60 \mu \mathrm{g} / \mathrm{mL})$, gentamycin $(30 \mu \mathrm{g} / \mathrm{mL})$, and/or chloramphenicol $(30 \mu \mathrm{g} / \mathrm{mL})$, rifampicin $(30 \mu \mathrm{g} / \mathrm{mL})$, zeocin $(100 \mu \mathrm{g} / \mathrm{mL})$, and/or streptomycin $(10 \mu \mathrm{g} / \mathrm{mL})$ as appropriate.

\section{$\underline{\text { Construction of mutant strains }}$}

Mutants in $A$. baylyi were made using natural transformation as described previously ${ }^{16}$. Briefly, mutant constructs were made by splicing-by-overlap (SOE) PCR to stich 1) $\sim 3 \mathrm{~kb}$ of the homologous region upstream of the gene of interest, 2) the mutation where appropriate (for deletion by allelic replacement with an antibiotic resistance cassette, or the fusion protein), and 3) the downstream region of homology. For a list of primers used to generate mutants in this study, see Supplemental Table 2. The upstream region was amplified using $F 1+R 1$ primers, and the downstream region was amplified using F2 + R2 primers. All antibiotic resistance (AbR) cassettes were amplified with ABD123 (ATTCCGGGGATCCGTCGAC) and ABD124 (TGTAGGCTGGAGCTGCTTC). Fusion proteins were amplified using the primers indicated in Supplemental Table 2. In-frame deletions were constructed using F1 + R1 primer pairs to amplify the upstream region and F2 + R2 primer pairs to amplify the downstream region with $\sim 20$ bp homology to the remaining region of the downstream region built into the R1 primer and $\sim 20 \mathrm{bp}$ homology to the upstream region built into the F2 primer. SOE PCR reactions were performed using a mixture of the upstream and downstream regions, and middle region where appropriate using F1 + R2 primers. SOE PCR products were added with $50 \mu \mathrm{l}$ of overnight-grown culture to $450 \mu \mathrm{l}$ of LB in $2 \mathrm{ml}$ round-bottom microcentrifuge tubes (USA Scientific) and grown at $30^{\circ} \mathrm{C}$ rotating on a roller drum for 1-3 hours. For $A b^{R}$-constructs, transformants were serially diluted and plated on LB and LB + antibiotic. For inframe deletions and protein fusion constructs, after the three-hour incubation, cells were incubated with $10 \mu \mathrm{l}$ of DNasel (New England Biolabs) for $5 \mathrm{~min}$ at room temperature before $450 \mu \mathrm{l}$ of LB was added. Transformations were grown for an additional hour before cells were diluted and $100 \mu \mathrm{l}$ of $10^{-6}$ dilution was plated on LB plates. In-frame deletions were confirmed by PCR using primers $\sim 150 \mathrm{bp}$ up and downstream of the introduced mutation, and fusions were confirmed by sequencing.

Mutants in $V$. cholerae were made by chitin-induced natural transformation exactly as previously described ${ }^{24,25}$. SOE products were generated exactly as described above. The chromosomally integrated $\mathrm{P}_{B A D}$ ectopic expression construct is described in detail in ref ${ }^{26}$.

\section{Natural transformation assays}

Assays were performed exactly as previously described ${ }^{27}$. Briefly, strains were grown overnight in LB broth at $30^{\circ} \mathrm{C}$ rolling. Then, $\sim 10^{8}$ cells were subcultured into fresh LB medium and $100 \mathrm{ng}$ of tDNA was added. In this study, a $\triangle$ ACIAD1551::Spec ${ }^{R}$ PCR product (with 3kb arms of homology) was used as the tDNA. Reactions were incubated with end-overend rotation at $30^{\circ} \mathrm{C}$ for 5 hours and then plated for quantitative culture on spectinomycin plates (to quantify transformants) and on plain LB plates (to quantify total viable counts). Data are reported as the transformation frequency, which is defined as the (CFU/mL of transformants) / (CFU/mL of total viable counts).

\section{$\underline{\text { Tn-seq Analysis }}$}

Transposon mutant libraries of $A$. baylyi were generated by electroporation of cells with pDL1093, a vector that allows for $\operatorname{Kan}^{R}$ mini-Tn10 mutagenesis 28,29 , and plating on kanamycin plates. Approximately 100,000 Tn mutants were scraped off of plates and pooled to generate the input transposon mutant library. This mutant library was then subjected to natural transformation in three separate replicates exactly as described above using three different sources of tDNA: a $\triangle$ ACIAD1551::Spec ${ }^{R}$ PCR product, an RpsL K43R $\left(\mathrm{Sm}^{\mathrm{R}}\right) \mathrm{PCR}$ product, or an RpoB PCR product from a spontaneous rifampicin resistant mutant. Following incubation with tDNA, reactions were split and outgrown in selective medium overnight (i.e. with the appropriate antibiotic 
added to select for transformants = "transformant pool") or grown overnight in nonselective medium (i.e. in plain LB medium = "total pool"). Sequencing libraries of the transposon-genomic junctions were generated for the Illumina platform using HTM-PCR exactly as previously described ${ }^{29,30}$. Sequencing data were mapped to the $V$. cholerae $\mathrm{N} 16961$ genome $^{31}$ and the relative abundance of $\mathrm{Tn}$ insertions in all samples was determined on the Galaxy platform ${ }^{32}$. Comparative analyses for Tn-seq were performed treating the "transformant pool" as the output and the "total pool" as the input to determine genes that were over- and under-represented following selection for transformants. Gene fitness was only assessed if a gene contained at least 1 transposon insertion in at least two out of the three replicates of the "total pool" samples. Also, the normalized abundance of insertions within a gene had to be greater than 0.01 in the "total pool" when averaged across all three replicates (where 1 is the expected normalized abundance for a "neutral" gene). These cutoffs allowed us to assess the phenotype of $\sim 83 \%$ of the genes (2747/3310) in the A. baylyi ADP1 genome. For visualization, the relative abundance of $\mathrm{Tn}$ insertions within each gene is plotted from the "transformant pool" relative to the "total pool".

\section{Pilin labeling, imaging, and quantification}

Pilin labeling was performed as described previously with some changes ${ }^{2,3}$. Briefly, $100 \mu$ l of overnight-grown cultures was added to $900 \mu \mathrm{l}$ of LB in $1.5 \mathrm{ml}$ microcentrifuge tube, and cells were grown at $30{ }^{\circ} \mathrm{C}$ rotating on a roller drum for $70 \mathrm{~min}$. Cells were then centrifuged at $18,000 \times g$ for $1 \mathrm{~min}$ and then resuspended in $50 \mu \mathrm{l}$ of LB before labeling with $25 \mu \mathrm{g} / \mathrm{ml}$ of AlexaFluor488 $\mathrm{C}_{5}$-maleimide (AF488-mal) (ThermoFisher) for 15 $\mathrm{min}$ at room temperature. Labeled cells were centrifuged, washed once with $100 \mu \mathrm{l}$ of LB without disrupting the pellet, and resuspended in 5-20 $\mu \mathrm{LB}$. Cell bodies were imaged using phase contrast microscopy while labeled pili were imaged using fluorescence microscopy on a Nikon Ti-2 microscope using a Plan Apo 100X objective, a GFP filter cube for pili, a Hamamatsu ORCAFlash4.0 camera, and Nikon NIS Elements Imaging Software. Cell numbers and the percent of cells making pili were quantified manually using Image $J^{33}$. All imaging was performed under 1\% UltraPure agarose (Invitrogen) pads made with phosphate-buffered saline (PBS) solution.

\section{Western blotting}

$\sim 10^{9}$ Cells from overnight cultures were concentrated into a pellet by centrifugation, and the culture supernatant was removed. Cell pellets were resuspended in $50 \mu \mathrm{l}$ PBS and then mixed with an equal volume of 2x SDS-PAGE sample buffer (125 mM Tris, pH 6.8, 20\% glycerol, 4\% SDS, 0.4\% bromophenol blue, and $10 \% \beta$-mercaptoethanol) and boiled using a heat block set to $100{ }^{\circ} \mathrm{C}$ for $10-15 \mathrm{~min}$. Proteins were separated on a $4-20 \%$ pre-cast polyacrylamide gel (Biorad) by SDS electrophoresis, electrophoretically transferred to a nitrocellulose membrane, and probed with mouse monoclonal a-FLAG antibodies (Sigma), mouse monoclonal $\alpha-G F P$ and/or mouse monoclonal $\alpha-R p o A$ (BioLegend) primary antibodies. Blots were then incubated with $\alpha-$ mouse IRDye secondary antibodies (Licor) and imaged using a Licor imaging system.

\section{Coimmunoprecipitation (pulldown) experiments}

Overnight cultures of cells grown in tubes in LB medium were diluted by $1 / 10$ into fresh LB for a total volume of $30 \mathrm{ml}$ or 50 $\mathrm{ml}$ in $125 \mathrm{ml}$ or $250 \mathrm{ml}$ volume flasks respectively. $30-50 \mathrm{ml}$ cultures were grown to exponential growth phase by shaking for $1.5 \mathrm{hr}$ at $30^{\circ} \mathrm{C}$. The total culture volume was then harvested at $10,000 \times g$ for $10 \mathrm{~min}$ at room temperature, and the supernatant was removed. Cell pellets were resuspended in $2 \mathrm{ml}$ of Buffer 1
(50 mM Tris-Cl pH 7.4, $150 \mathrm{mM} \mathrm{NaCl}, 1 \mathrm{mM}$ EDTA) and transferred to $2 \mathrm{ml}$ volume microcentrifuge tubes and centrifuged at $18,000 \times g$ for $1 \mathrm{~min}$. Cells were washed once more with $2 \mathrm{ml}$ of Buffer 1 , and washed pellets were resuspended in $1 \mathrm{ml}$ of Buffer 2 (50 mM Tris-Cl pH 7.4, $150 \mathrm{mM} \mathrm{NaCl}, 1 \mathrm{mM}$ EDTA, $10 \mathrm{mM}$ $\mathrm{MgCl}_{2}, 0.1 \%$ Triton X-100, 2\% glycerol). To lyse cells, 4200 units of Ready-Lyse lysozyme (Lucigen), 30 units of DNase I (New England Biolabs), and $10 \mu \mathrm{l}$ of concentrated protease inhibitor cocktail (Sigma) (one pellet dissolved in $500 \mu$ l of Buffer 1) were added to cell suspensions and incubated at room temperature for $45 \mathrm{~min}$. Cell debris was removed by centrifugation at $10,000 \times \mathrm{g}$ for $5 \mathrm{~min}$ at $4{ }^{\circ} \mathrm{C}$. $50 \mu \mathrm{l}$ of cell lysates were set aside and used as an "input" sample. $50 \mu$ laliquots of $\alpha-F L A G$ magnetic bead slurry (Sigma) or a-GFP magnetic bead slurry (MBL biotech) in $1.5 \mathrm{ml}$ microcentrifuge tubes were washed three times with $1 \mathrm{ml}$ of Buffer 2 using a magnetic collection stand. $1 \mathrm{ml}$ of cell lysates was added to washed magnetic beads and subjected to end-over-end rotation at $4{ }^{\circ} \mathrm{C}$ for $2 \mathrm{hr}$. Beads were then washed three times with $0.5 \mathrm{ml}$ of Buffer 2, with 10 min incubations in Buffer 2 at $4{ }^{\circ} \mathrm{C}$ between each wash step. Beads were briefly washed a $4^{\text {th }}$ time with $0.5 \mathrm{ml}$ Buffer 2. To elute proteins from $\alpha$-FLAG beads, $100 \mu$ l of elution buffer (150 $\mu \mathrm{g} / \mathrm{ml}$ 3X-FLAG peptide, Sigma, in Buffer 2) was added and samples were subjected to end-over-end rotation at 4 ${ }^{\circ} \mathrm{C}$ for $30 \mathrm{~min}$. To elute proteins from $\alpha$-GFP beads, beads were resuspended in $50 \mu \mathrm{l}$ PBS, 2x SDS-PAGE sample buffer was added to tubes, and samples were boiled as described above. Eluates and input samples were subjected to western blotting as described above.

\section{Measuring GFP fluorescence in reporter strains}

$V$. cholerae reporter strains harboring $\mathrm{P}_{c p i A}$-GFP were grown to late log in LB medium with or without $0.2 \%$ arabinose as indicated. Cells were then washed once in instant ocean medium (7g/L; Aquarium Systems) and transferred to a 96-well plate. Fluorescence was then determined on a Biotek $\mathrm{H} 1 \mathrm{M}$ plate reader with monochromater set to $500 \mathrm{~nm}$ for excitation and $540 \mathrm{~nm}$ for emission.

\section{Fluorescent DNA binding/uptake}

A $\sim 7 \mathrm{~kb}$ PCR product was fluorescently labeled as described previously ${ }^{11}$ using the Cy3 LabellT kit (Mirus Biosciences) as per manufacturer recommendations. For the parent strain, $1 \mu \mathrm{l}(100 \mathrm{ng})$ of Cy3-DNA was added to $900 \mu \mathrm{l}$ of LB in a $1.5 \mathrm{ml}$ microcentrifuge tube along with $100 \mu \mathrm{l}$ of overnightgrown cultures, and cells were grown at $30^{\circ} \mathrm{C}$ rotating on a roller drum for $70 \mathrm{~min}$. Pili were then labeled as described above.

To visualize DNA-binding in the pilT mutant, cells were grown as described above, but $1 \mu \mathrm{l}(100 \mathrm{ng})$ of Cy3-DNA was added to cells along with AF488-mal and incubated for $25 \mathrm{~min}$ before washing. Cells were imaged using the same microscopy setup described above, using a dsRed filter cube to image Cy3DNA.

\section{Phylogenetic analysis}

TfpB homologues were identified by BLAST using 43 manually selected Gammaproteobacteria genomes ${ }^{34}$ through Integrated Microbial Genomes and Microbiomes online resources $(\text { IMG })^{35}$ resulting in 209 protein sequences. The FtsK protein from A. baylyi ADP1 was added manually and used as an outgroup. Through the NGPhylogeny.fr server ${ }^{36}$, sequences were aligned using the default parameters of MAFFT ${ }^{37}$, and phylogenetic tree construction was performed on the aligned sequences using the default parameters of FastTree software ${ }^{38,39}$ set to perform 100 bootstraps ${ }^{40}$. The resulting tree was visualized using the Interactive Tree of Life (iTOL) visualization software ${ }^{41}$, from which trees were exported for publication. 
Acknowledgements: We would like to thank E. Geisinger for $A$. baylyi ADP1 ATCC33305 wildtype strain, and we would like to thank K. Hummels and B. Bratton for helpful suggestions on phylogenetic analysis. CKE is a Damon Runyon Fellow supported by the Damon Runyon Cancer Research Foundation (DRG-2385$20)$. This work was supported in part by the National Science Foundation, through the Center for the Physics of Biological Function (PHY-1734030). This work was supported by grant R35GM128674 from the National Institutes of Health awarded to $A B D$ and the National Institutes of Health Pioneer Award 1DP1Al124669-01 awarded to ZG.

Author contributions: $\mathrm{CKE}$ and $\mathrm{ABD}$ designed and coordinated the overall study. CKE, TND, CAK and ABD performed the experiments. All authors analyzed and interpreted data. CKE and ABD wrote the manuscript with help from ZG and JWS.

Competing interests: The authors declare no competing interests.

Data availability statement: The data that support the findings of this study are available from the corresponding authors upon request.

\section{References}

1. Burrows, L. L. Pseudomonas aeruginosa twitching motility: type IV pili in action. Annu Rev Microbiol 66, 493520 (2012).

2. Ellison, C. K.. et al. Obstruction of pilus retraction stimulates bacterial surface sensing. Science. 358, 535538 (2017).

3. Ellison, C. K., Dalia, T. N., Dalia, A. B. \& Brun, Y. V. Realtime microscopy and physical perturbation of bacterial pili using maleimide-conjugated molecules. Nat. Protoc. 14, 1803-1819

(2019).

4. Denise, R., Abby, S. S. \& Rocha, E. P. C. Diversification of the type IV filament superfamily into machines for adhesion, protein secretion, DNA uptake, and motility. PLOS Biol. 17, e3000390 (2019).

5. Craig, L., Forest, K. T. \& Maier, B. Type IV pili: dynamics, biophysics and functional consequences. Nat. Rev. Microbiol. 1 (2019). doi:10.1038/s41579-019-0195-4

6. Merz, A. J., So, M. \& Sheetz, M. P. Pilus retraction powers bacterial twitching motility. Nature 407, 98-102 (2000).

7. Snyder, R. A. et al. Surface sensing stimulates cellular differentiation in Caulobacter crescentus. Proc. Natl. Acad. Sci. (2020). doi:10.1073/PNAS.1920291117

8. Siryaporn, A. et al. Surface attachment induces Pseudomonas aeruginosa virulence. Proc. Natl. Acad. Sci. 111, 16860-16865 (2014).

9. Persat, A., Inclan, Y. F., Engel, J. N., Stone, H. A. \& Gitai, Z. Type IV pili mechanochemically regulate virulence factors in Pseudomonas aeruginosa. Proc. Natl. Acad. Sci. 112, 7563-7568 (2015).

10. Seitz, P. \& Blokesch, M. DNA-uptake machinery of naturally competent Vibrio cholerae. Proc. Natl. Acad. Sci. U. S. A. 110, 17987-92 (2013).

11. Ellison, C. K. et al. Retraction of DNA-bound type IV competence pili initiates DNA uptake during natural transformation in Vibrio cholerae. Nat. Microbiol. 3, 773780 (2018).

12. Harding, C. M. et al. Acinetobacter baumannii strain M2 produces type IV Pili which play a role in natural transformation and twitching motility but not surface- associated motility. MBio 4, (2013). doi: 10.1128/mBio.00360-13

13. Godeux, A. S. et al. Fluorescence-based detection of natural transformation in drug-resistant acinetobacter baumannii. J. Bacteriol. 200, (2018). doi: 10.1128/JB.00181-18

14. Metzgar, D. et al. Acinetobacter sp. ADP1: An ideal model organism for genetic analysis and genome engineering. Nucleic Acids Res. 32, 5780-5790 (2004).

15. van Opijnen, T., Bodi, K. L. \& Camilli, A. Tn-seq: Highthroughput parallel sequencing for fitness and genetic interaction studies in microorganisms. Nat. Methods 6, 767-772 (2009).

16. Chlebek, J. L. et al. PilT and PilU are homohexameric ATPases that coordinate to retract type IVa pili. PLOS Genet. 15, e1008448 (2019).

17. McCallum, M., Tammam, S., Khan, A., Burrows, L. L. \& Howell, P. L. The molecular mechanism of the type IVa pilus motors. Nat. Commun. 8, 15091 (2017).

18. Kelley, L. A., Mezulis, S., Yates, C. M., Wass, M. N. \& Sternberg, M. J. E. The Phyre2 web portal for protein modeling, prediction and analysis. Nat. Protoc. 10, 845858 (2015).

19. Altschul, S. F., Gish, W., Miller, W., Myers, E. W. \& Lipman, D. J. Basic local alignment search tool. J. Mol. Biol. 215, 403-410 (1990).

20. Meibom, K. L., Blokesch, M., Dolganov, N. A., Wu, C.-Y. \& Schoolnik, G. K. Chitin Induces Natural Competence in Vibrio cholerae. Science (80-. ). 310, 1824-1827 (2005).

21. Schuhmacher, D. A. \& Klose, K. E. Environmental signals modulate ToxT-dependent virulence factor expression in Vibrio cholerae. J. Bacteriol. 181, 1508-1514 (1999).

22. Chung, I. Y., Jang, H. J., Bae, H. W. \& Cho, Y. H. A phage protein that inhibits the bacterial ATPase required for type IV pilus assembly. Proc. Natl. Acad. Sci. U. S. A. 111, 11503-11508 (2014).

23. Shah, M. et al. A phage-encoded anti-activator inhibits quorum sensing in Pseudomonas aeruginosa. Mol. Cell (2021). doi:10.1016/j.molcel.2020.12.011

24. Dalia, A. B., McDonough, E. \& Camilli, A. Multiplex genome editing by natural transformation. Proc. Natl. Acad. Sci. U. S. A. 111, 8937-42 (2014).

25. Dalia, A. B. Natural Cotransformation and Multiplex Genome Editing by Natural Transformation (MuGENT) of Vibrio cholerae. in Methods in molecular biology (Clifton, N.J.) 1839, 53-64 (2018).

26. Dalia, T. N., Chlebek, J. L. \& Dalia, A. B. A modular chromosomally integrated toolkit for ectopic gene expression in Vibrio cholerae. Sci. Rep. 10, 1-8 (2020).

27. Nero, T. M. et al. ComM is a hexameric helicase that promotes branch migration during natural transformation in diverse Gram-negative species. Nucleic Acids Res. 46, 6099-6111 (2018).

28. Shull, L. M. \& Camilli, A. Transposon sequencing of vibrio cholerae in the infant rabbit model of cholera. in Methods in Molecular Biology 1839, 103-116 (Humana Press Inc., 2018).

29. Mcdonough, E., Lazinski, D. W. \& Camilli, A. Identification of in vivo regulators of the Vibrio choleraexds gene using a high-throughput genetic selection. Mol. Microbiol. 92, 302-315 (2014).

30. Lazinski, D. W. \& Camilli, A. Homopolymer tail-mediated ligation PCR: A streamlined and highly efficient method for DNA cloning and library construction. Biotechniques 54, 25-34 (2013). 
31. Heidelberg, J. F. et al. DNA sequence of both chromosomes of the cholera pathogen Vibrio cholerae. Nature 406, 477-483 (2000).

32. Afgan, E. et al. The Galaxy platform for accessible, reproducible and collaborative biomedical analyses: 2016 update. Nucleic Acids Res. 44, W3-W10 (2016).

33. Schneider, C. A., Rasband, W. S. \& Eliceiri, K. W. NIH Image to ImageJ: 25 years of image analysis. Nat. Methods 9, 671-675 (2012).

34. Mukherjee, S. et al. Genomes OnLine database (GOLD) v.7: Updates and new features. Nucleic Acids Res. 47, D649-D659 (2019).

35. Chen, I. M. A. et al. IMG/M v.5.0: An integrated data management and comparative analysis system for microbial genomes and microbiomes. Nucleic Acids Res. 47, D666-D677 (2019).

36. Lemoine, F. et al. NGPhylogeny.fr: New generation phylogenetic services for non-specialists. Nucleic Acids
Res. 47, W260-W265 (2019).

37. Katoh, K. \& Standley, D. M. MAFFT multiple sequence alignment software version 7: Improvements in performance and usability. Mol. Biol. Evol. 30, 772-780 (2013).

38. Price, M. N., Dehal, P. S. \& Arkin, A. P. Fasttree: Computing large minimum evolution trees with profiles instead of a distance matrix. Mol. Biol. Evol. 26, 16411650 (2009).

39. Price, M. N., Dehal, P. S. \& Arkin, A. P. FastTree 2 Approximately maximum-likelihood trees for large alignments. PLoS One 5, e9490 (2010).

40. Lemoine, F. et al. Renewing Felsenstein's phylogenetic bootstrap in the era of big data. Nature 556, 452-456 (2018).

41. Letunic, I. \& Bork, P. Interactive Tree of Life (iTOL) v4: Recent updates and new developments. Nucleic Acids Res. 47, W256-W259 (2019). 


\section{Supplemental Materials for:}

\section{Acinetobacter baylyi regulates type IV pilus synthesis by employing two extension motors and a motor protein inhibitor}

Courtney K. Ellison ${ }^{1,2^{*}}$, Triana N. Dalia ${ }^{3}$, Catherine A. Klancher ${ }^{3}$, Joshua W. Shaevitz ${ }^{1^{*}}$, Zemer Gitai $^{2^{*}}$, and Ankur B. Dalia ${ }^{3^{*}}$

1. Lewis-Sigler Institute for Integrative Genomics, Princeton University, Princeton, NJ

2. Department of Molecular Biology, Princeton University, Princeton, NJ

3. Department of Biology, Indiana University, Bloomington, IN

*Correspondence to: c.ellison@princeton.edu, shaevitz@princeton.edu, zgitai@princeton.edu, ankdalia@indiana.edu

This file includes:

Supplemental Figures 1-4

Supplemental Tables 1-2 

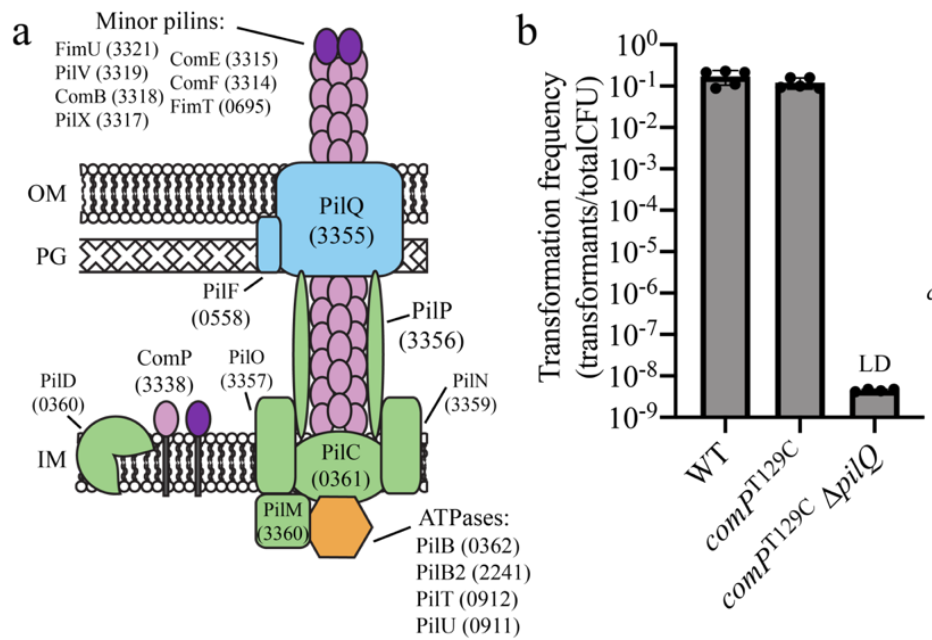

$\mathrm{c}$

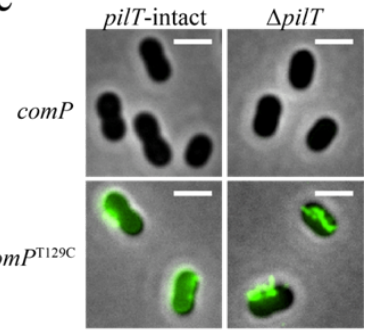

Supplemental figure 1. The strain for labeling T4P in A. baylyi is fully functional. (a) Schematic of assembled T4P components found in A. baylyi. Numbers in parentheses are ACIAD numbers associated with each component. OM, outer membrane; PG, peptidoglycan; IM, inner membrane. (b) Natural transformation assays of indicated strains. Each data point represents a biological replicate and bar graphs indicate the mean \pm SD. The transformation frequency of the $\triangle$ pilQ strain was below the limit of detection, indicated by LD. (c) Representative images of indicated strains labeled with AF488-mal with background fluorescence subtracted. Scale bars, $2 \mu \mathrm{m}$. 
bioRxiv preprint doi: https://doi.org/10.1101/2020.09.28.317149; this version posted January 30, 2021. The copyright holder for this preprint (which was not certified by peer review) is the author/funder. All rights reserved. No reuse allowed without permission.

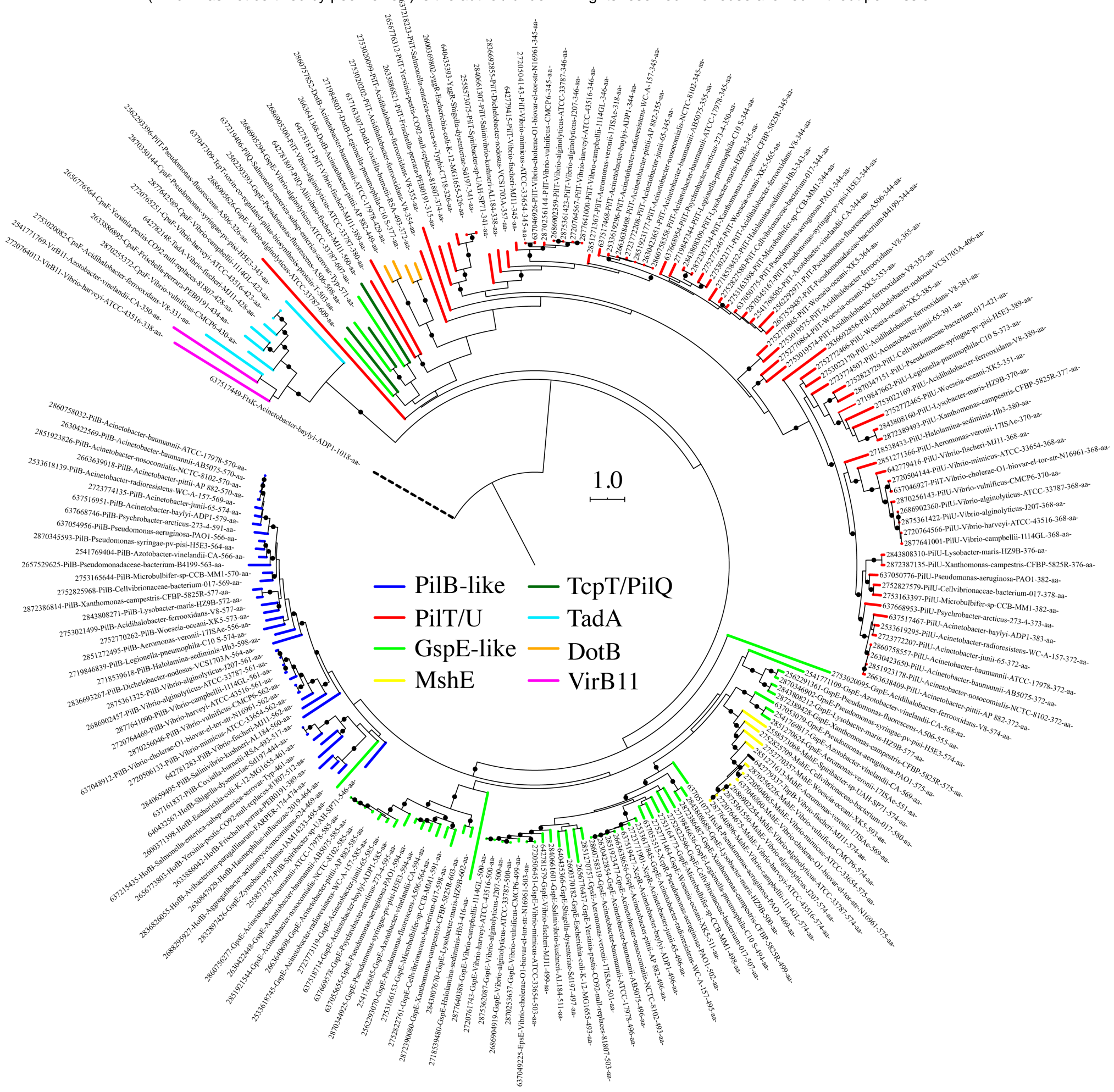

Supplemental figure 2. TfpB clusters with a group of other GspE-like proteins that are distinct from PilB proteins. A rooted phylogeny of TfpB homologues shown in Figure $2 \mathrm{~d}$ with labels. Labels indicate IMG GenelD, annotated protein name, species, protein size. Nodes with bootstrap values greater than or equal to $70 \%$ are indicated by black circles. 


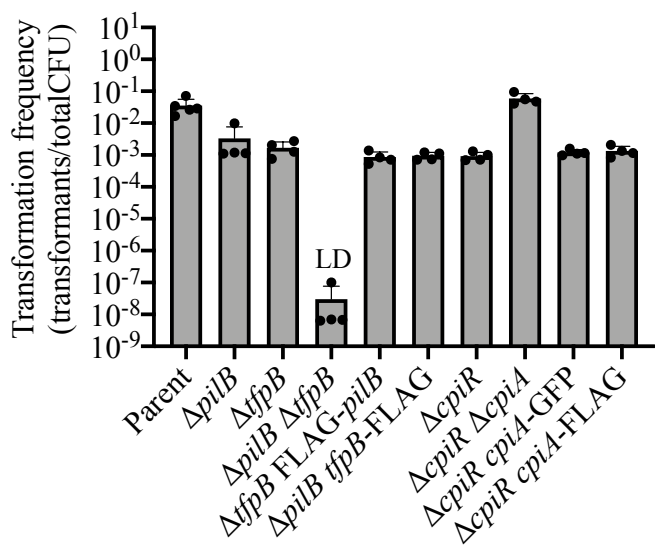

Supplemental figure 3. Natural transformation assays of indicated strains. Each data point represents a biological replicate and bar graphs indicate the mean $\pm \mathrm{SD}$. The transformation frequency of the $\Delta$ pilB $\Delta t f p B$ strain was below the limit of detection, indicated by LD. 


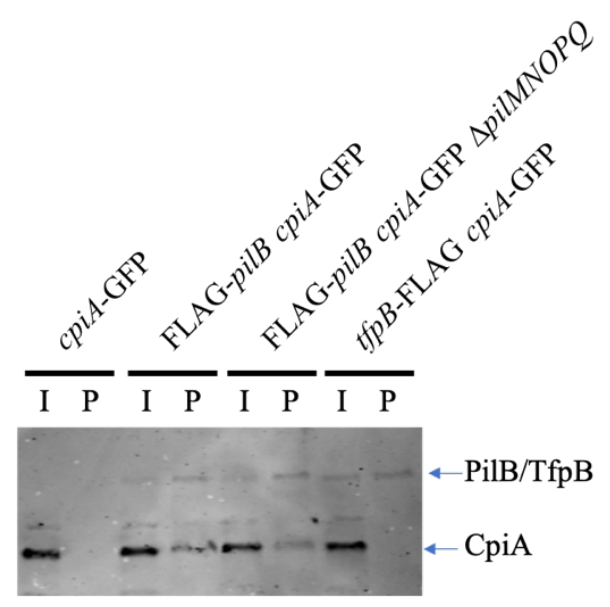

Supplemental figure 4. CpiA specifically interacts with PilB to inhibit its activity. Western blot showing coimmunoprecipitation experiments where FLAG-PilB or TfpB-FLAG were used as the bait proteins to test for interaction with CpiA-GFP as the prey protein in $\Delta c p i R$ mutant backgrounds. I, input sample; $P$, pulldown (coimmunoprecipitation) sample. 
Supplemental table 1. Bacterial strains used in this study.

\begin{tabular}{|c|c|c|c|c|c|}
\hline CE\# & ZG\# & $\begin{array}{l}\text { TND/ } \\
\text { SAD\# }\end{array}$ & $\begin{array}{l}\text { Strain name in } \\
\text { manuscript }\end{array}$ & Genotype & $\begin{array}{l}\text { Figure ('S' } \\
\text { denotes } \\
\text { supplemental } \\
\text { figure) }\end{array}$ \\
\hline CE1 & & SAD631 & Wildtype (WT) & Acinetobacter baylyi ADP1 & S1B, S1C \\
\hline CE100 & & SAD2537 & $\begin{array}{l}\text { Pil-cys or } \\
\text { Parent }\end{array}$ & ADP1 comP $P^{\top 129 C}$ & $\begin{array}{l}\text { 1A, 1C, 1D, 2A, } \\
3 B, S 1 B, S 1 C \\
\text { S3 }\end{array}$ \\
\hline CE329 & ZG1709 & & $\Delta p i l T$ & ADP1 $\Delta$ pilT & S1C \\
\hline \multirow[t]{2}{*}{ CE317 } & & TND0779 & $\begin{array}{l}\text { Pil-cys } \Delta \text { pilT or } \\
\text { Parent }\end{array}$ & ADP1 comP $P^{\top 129 C} \Delta$ pilT::spec & $1 \mathrm{~A}, 1 \mathrm{C}, 2 \mathrm{~B}, \mathrm{S1C}$ \\
\hline & & TND0114 & $\Delta c o m P$ & ADP1 $\Delta$ comP::kan & $2 \mathrm{~A}$ \\
\hline CE150 & ZG1680 & & $\Delta p i l C$ & ADP1 $\operatorname{comP}^{\mathrm{T} 129 \mathrm{C}} \Delta$ pilC & $1 \mathrm{C}, 1 \mathrm{D}$ \\
\hline CE16 & ZG1678 & & $\Delta$ pilY1 & ADP1 $\operatorname{comP} P^{\top 129 C} \Delta p i l Y 1$ & $1 \mathrm{C}, 1 \mathrm{D}$ \\
\hline CE66 & ZG1679 & & $\Delta$ pilQ & ADP1 $\operatorname{com} P^{\top 129 C} \Delta p i l Q$ & $1 \mathrm{C}, 1 \mathrm{D}, \mathrm{S} 1 \mathrm{~B}$ \\
\hline CE286 & & TND2544 & $\triangle$ comEA & $\begin{array}{l}\text { ADP1 comP } \\
\Delta \text { comEA::kan }\end{array}$ & $1 \mathrm{C}, 1 \mathrm{D}$ \\
\hline CE287 & & TND2546 & $\triangle$ comEC & $\begin{array}{l}\text { ADP1 comP } P^{\top 129 C} \\
\Delta \text { comEC::kan }\end{array}$ & $1 \mathrm{C}, 1 \mathrm{D}$ \\
\hline CE289 & & TND2556 & $\Delta$ comM & ADP1 comP $P^{\top 129 C} \Delta c o m M:: k a n$ & $1 \mathrm{C}, 1 \mathrm{D}$ \\
\hline CE22 & ZG1683 & & $\Delta$ pilB & ADP1 comP ${ }^{\top 129 C} \Delta$ pilB & $2 \mathrm{~A}, 2 \mathrm{C}, 4 \mathrm{C}, \mathrm{S} 3$ \\
\hline CE67 & ZG1685 & & $\Delta t f p B$ & ADP1 $c o m P^{\top 129 C} \Delta t f p B$ & $2 \mathrm{~A}, 2 \mathrm{C}, 4 \mathrm{C}, \mathrm{S} 3$ \\
\hline CE54 & ZG1684 & & $\Delta p i l B \Delta t f p B$ & $\begin{array}{l}\text { ADP1 comP } \\
\Delta t f p B:: k a n\end{array}$ & $2 \mathrm{~A}, 2 \mathrm{C}, 4 \mathrm{C}, \mathrm{S} 3$ \\
\hline CE310 & ZG1673 & & $\Delta$ pilB $\Delta$ pilT & $\begin{array}{l}\text { ADP1 comP } \\
\Delta \text { pilT::spec }\end{array}$ & $2 \mathrm{~B}, 2 \mathrm{C}, 4 \mathrm{~B}$ \\
\hline CE311 & ZG1674 & & $\Delta t f p B \Delta p i l T$ & $\begin{array}{l}\text { ADP1 comP }{ }^{T 129 C} \Delta t f p B \\
\Delta \text { pilT::spec }\end{array}$ & $2 \mathrm{~B}, 2 \mathrm{C}, 4 \mathrm{~B}$ \\
\hline CE316 & ZG1677 & & $\begin{array}{l}\Delta \text { pilB } \Delta t f p B \\
\Delta \text { pilT }\end{array}$ & $\begin{array}{l}\text { ADP1 comP }{ }^{\mathrm{T} 129 \mathrm{C}} \Delta \text { pilB } \\
\Delta t f p B:: k a n \Delta \text { pilT::spec }\end{array}$ & $2 \mathrm{~B}, 2 \mathrm{C}$ \\
\hline CE263 & & TND1201 & $\Delta c p i R$ & ADP1 comP $P^{129 C} \Delta c p i R:: k a n$ & $3 B, 4 A, S 3$ \\
\hline \multirow[t]{6}{*}{ CE264 } & & SAD2792 & $\Delta c p i R \Delta c p i A$ & ADP1 comP ${ }^{\top 129 C} \Delta c p i R A:: k a n$ & $3 B, 4 A, S 3$ \\
\hline & & TND2260 & $\mathrm{P}_{\text {tac-cpiA }}$ & $\begin{array}{l}\text { ADP1 comP }{ }^{T 129 C} \\
\text { igACIAD0096- } \\
\text { ACIAD0098::Cm } \text { Cm }^{R} \text { Ptac-CpiA }\end{array}$ & 3B \\
\hline & & TND2093 & $\begin{array}{l}\mathrm{P}_{\text {cpiA-GFP }} \\
\text { Parent }\end{array}$ & $\begin{array}{l}\text { V. cholerae E7946 Sm } \\
\text { LlacZ::SpecR-P } P_{\text {cpiA-gfp }}\end{array}$ & $3 C$ \\
\hline & & TND2126 & $\begin{array}{l}\mathrm{P}_{c p i A}-G F P P_{B A D^{-}} \\
\text {cpiR }\end{array}$ & 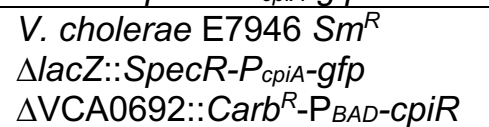 & $3 C$ \\
\hline & & TND1335 & cpiA-FLAG & $\begin{array}{l}\text { ADP1 comP }{ }^{T 129 C} \text { cpiA-3X } \\
\text { FLAG }\end{array}$ & $3 \mathrm{D}$ \\
\hline & & TND1284 & $\begin{array}{l}\text { cpiA-FLAG } \\
\Delta c p i R\end{array}$ & $\begin{array}{l}\text { ADP1 comP }{ }^{\top 129 \mathrm{C}} \text { cpiA-3X } \\
\text { FLAG } \Delta c p i R:: k a n\end{array}$ & $3 \mathrm{D}, \mathrm{S3}$ \\
\hline CE282 & & SAD2808 & $\Delta p i l B \Delta c p i R$ & $\begin{array}{l}\text { ADP1 comP }{ }^{\top 129 C} \Delta \text { pilB } \\
\Delta \text { cpiR::kan }\end{array}$ & $4 \mathrm{~A}, 4 \mathrm{C}$ \\
\hline CE283 & & SAD2806 & $\Delta t f p B \Delta c p i R$ & $\begin{array}{l}\text { ADP1 comP } \\
\Delta \text { cpiR::kan }\end{array}$ & $4 \mathrm{~A}, 4 \mathrm{C}$ \\
\hline CE284 & & SAD2809 & $\begin{array}{l}\Delta p i l B \Delta c p i R \\
\Delta c p i A\end{array}$ & $\begin{array}{l}\text { ADP1 comP }{ }^{\mathrm{T} 129 \mathrm{C}} \Delta \text { pilB } \\
\Delta \text { cpiRA::kan }\end{array}$ & $4 \mathrm{~A}$ \\
\hline CE285 & & SAD2807 & $\begin{array}{l}\Delta t f p B \Delta c p i R \\
\Delta c p i A\end{array}$ & $\begin{array}{l}\text { ADP1 comP } \\
\Delta \text { cpiRA::kan }\end{array}$ & $4 \mathrm{~A}, 4 \mathrm{C}$ \\
\hline
\end{tabular}




\begin{tabular}{|c|c|c|c|c|c|}
\hline CE265 & & SAD2645 & $\Delta c p i R \Delta p i l T$ & $\begin{array}{l}\text { ADP1 comP }{ }^{\top 129 C} \Delta c p i R:: k a n \\
\Delta \text { pilT::spec }\end{array}$ & $4 \mathrm{~A}, 4 \mathrm{~B}$ \\
\hline CE266 & & SAD2810 & $\begin{array}{l}\Delta c p i R \Delta c p i A \\
\Delta \text { pilT }\end{array}$ & $\begin{array}{l}\text { ADP1 comP }{ }^{\top 129 C} \Delta c p i R A:: k a n \\
\Delta \text { pilT::spec }\end{array}$ & $4 \mathrm{~A}$ \\
\hline CE302 & & SAD2822 & $\begin{array}{l}\Delta p i l B \Delta c p i R \\
\Delta \text { pilT }\end{array}$ & $\begin{array}{l}\text { ADP1 comP }{ }^{\top 129 C} \Delta \text { pilB } \\
\Delta \text { cpiR::kan } \\
\Delta \text { pilT::spec }\end{array}$ & $4 \mathrm{~A}, 4 \mathrm{~B}$ \\
\hline CE303 & & SAD2820 & $\begin{array}{l}\Delta t f p B \Delta c p i R \\
\Delta p i l T\end{array}$ & $\begin{array}{l}\text { ADP1 comP }{ }^{\top 129 C} \Delta t f p B \\
\Delta \text { cpiR::kan } \Delta \text { pilT::spec }\end{array}$ & $4 \mathrm{~A}, 4 \mathrm{~B}$ \\
\hline CE304 & & SAD2823 & $\begin{array}{l}\Delta \text { pilB } \triangle c p i R \\
\Delta c p i A \Delta \text { pilT }\end{array}$ & $\begin{array}{l}\text { ADP1 comP }{ }^{\top 129 C} \Delta \text { pilB } \\
\Delta \text { cpiRA::kan } \Delta \text { pilT::spec }\end{array}$ & $4 \mathrm{~A}$ \\
\hline \multirow[t]{5}{*}{ CE305 } & & SAD2821 & $\begin{array}{l}\Delta t f p B \Delta c p i R \\
\Delta c p i A \Delta \text { pilT }\end{array}$ & $\begin{array}{l}\text { ADP1 comP } P^{\top 129 C} \Delta t f p B \\
\Delta c p i R A:: k a n \Delta \text { pilT::spec }\end{array}$ & $4 \mathrm{~A}, 4 \mathrm{~B}$ \\
\hline & & TND2904 & $\begin{array}{l}\Delta t f p B \text { FLAG- } \\
\text { pilB }\end{array}$ & $\begin{array}{l}\text { ADP1 comP }{ }^{\top 129 C} \Delta t f p B:: k a n \\
3 \text { X FLAG-pilB }\end{array}$ & S3 \\
\hline & & TND2892 & $\begin{array}{l}\Delta p i l B t f p B- \\
\text { FLAG }\end{array}$ & $\begin{array}{l}\text { ADP1 comP }{ }^{\top 129 C} \Delta \text { pilB::kan } \\
\text { tfpB-3X FLAG }\end{array}$ & S3 \\
\hline & & TND1296 & $\begin{array}{l}\text { cpiA-GFP } \\
\Delta \text { cpiR }\end{array}$ & $\begin{array}{l}\text { ADP1 comP }{ }^{\top 129 C} \text { cpiA-GFP } \\
\Delta \text { cpiR::kan }\end{array}$ & S3, S4 \\
\hline & & TND2337 & FLAG-pilB & $\begin{array}{l}\text { ADP1 comP }{ }^{\top 129 C} 3 X \text { FLAG- } \\
\text { pilB }\end{array}$ & $3 \mathrm{D}$ \\
\hline \multirow[t]{2}{*}{ CE608 } & ZG1784 & & $\begin{array}{l}\text { FLAG-pilB } \\
\Delta c p i R\end{array}$ & $\begin{array}{l}\text { ADP1 comP } \\
\text { pilB } \Delta \text { cpiR::kan } 3 \mathrm{X} \text { FLAG- }\end{array}$ & $3 \mathrm{D}, 4 \mathrm{D}$ \\
\hline & & TND2383 & $\begin{array}{l}\text { FLAG-pilB cpiA- } \\
\text { GFP } \Delta c p i R\end{array}$ & $\begin{array}{l}\text { ADP1 comP }{ }^{\top 129 C} 3 \mathrm{X} \text { FLAG- } \\
\text { pilB cpiA-GFP } \Delta \text { cpiR::kan }\end{array}$ & $4 \mathrm{D}, \mathrm{S} 4$ \\
\hline CE626 & ZG1785 & & $\begin{array}{l}\text { FLAG-pilB cpiA- } \\
\text { GFP } \triangle c p i R \\
\Delta \text { pilMNOPQ }\end{array}$ & $\begin{array}{l}\text { ADP1 comP }{ }^{\top 129 C} 3 X \text { FLAG- } \\
\text { pilB cpiA-GFP } \Delta \text { cpiR::kan } \\
\Delta \text { pilMNOPQ::zeo }\end{array}$ & S4 \\
\hline CE656 & ZG1786 & & $\begin{array}{l}\text { FLAG-tfpB } \\
\text { cpiA-GFP } \\
\Delta \text { cpiR }\end{array}$ & $\begin{array}{l}\text { ADP1 comP }{ }^{\top 129 C} \text { tfpB-3X } \\
\text { FLAG cpiA-GFP } \Delta \text { cpiR::kan }\end{array}$ & S4 \\
\hline
\end{tabular}

CE strains available upon request from CKE, ZG strains available upon request from ZG, TND or SAD strains available upon request from $A B D$. 
Supplemental table 2. Primers used for strain construction.

\begin{tabular}{|c|c|c|}
\hline $\begin{array}{l}\text { Primer } \\
\text { name }\end{array}$ & $\begin{array}{l}\text { Primer sequence } 5^{\prime} \rightarrow 3^{\prime} \text { (overlapping regions underlined, point } \\
\text { mutations in bold) }\end{array}$ & Description \\
\hline DOG0175 & AAACTATCCAGATAAGGGAAAGC & comP F1 \\
\hline CEdalia87 & GAAGTTGTCGTACATTTCCAACATACAGCGCCACTAGCATATG & comPT129C R1 \\
\hline CEdalia88 & CATATGCTAGTGGCGCTGTATGTTGGAAATGTACGACAACTTC & comPT129C F2 \\
\hline DOG0178 & AGGATCTGTAATGACGGGTTGAG & comP R2 \\
\hline DOG0176 & GTCGACGGATCCCCGGAATCATAAAATTTCTCCACCAATGTTG & $\Delta$ comP R1 \\
\hline DOG0177 & $\begin{array}{l}\text { GAAGCAGCTCCAGCCTACATGATAGTAGTACTATATGGCTTTAAA } \\
\text { AG }\end{array}$ & $\Delta$ comP F2 \\
\hline ABD123 & ATTCCGGGGATCCGTCGAC & AbR cassette $F$ \\
\hline ABD124 & TGTAGGCTGGAGCTGCTTC & AbR cassette $R$ \\
\hline BBC1934 & GTTACAAAGTCAGGGACGTAAAG & $\Delta$ pilT F1 \\
\hline BBC1935 & GTCGACGGATCCCCGGAATATCCATATTTTCCCCGAAGATCG & $\Delta$ pilT R1 \\
\hline BBC1936 & GAAGCAGCTCCAGCCTACATAAGAATAACGCTACTCGATCTG & $\Delta$ pilT F2 \\
\hline BBC1939 & GGTATTCAGATTGATCGTCAGTTAG & $\Delta$ pilT R2 \\
\hline CE389 & TCAGGAAGTTGCCTGAACCTGA & $\Delta$ pilC F1 \\
\hline CE390 & $\begin{array}{l}\text { ACAGAGCCCATTTGGAAAATTGGTGGCATTACTTGCGTTTTTTTT } \\
\text { GCT }\end{array}$ & $\Delta$ pilC R1 \\
\hline CE391 & $\begin{array}{l}\text { AGCAAAAAAAACGCAAGTAATGCCACCAATTTTCCAAATGGGCTC } \\
\text { TGT }\end{array}$ & $\Delta$ pilC F2 \\
\hline CE392 & TTGAAAAGCTGGCTGGCCTTC & $\Delta$ pilC R2 \\
\hline CE136 & TTGGTCGATAATGCAGATCAGCT & $\Delta$ pilY1 F1 \\
\hline CE137 & $\begin{array}{l}\text { GGGGTGCTTTGCTCATACCATTTTAAGAGATACTGAGTGTATATC } \\
\text { GATTTTTTCAT }\end{array}$ & $\Delta$ pilY1 R1 \\
\hline
\end{tabular}




\begin{tabular}{|c|c|c|}
\hline CE138 & $\begin{array}{l}\text { ATGAAAAAATCGATATACACTCAGTATCTCTTAAAATGGTATGAG } \\
\text { CAAAGCACCCC }\end{array}$ & $\Delta$ pilY1 F2 \\
\hline CE139 & GCAGGGATATCAGATTTTAACTGTGC & $\Delta$ pilY1 R2 \\
\hline CE85 & AATAAGAGCGAATAGCAAACTAATTGTCG & $\Delta$ pilQ F1 \\
\hline CE340 & $\begin{array}{l}\text { TTTCCAACAATAGTGTCATTAACTATTCGAGTCGTAAAAACGTTAA } \\
\text { ААTCTGTTCTCAT }\end{array}$ & $\begin{array}{l}\Delta \text { pilQ R1 (clean } \\
\text { deletion) }\end{array}$ \\
\hline CE341 & $\begin{array}{l}\text { ATGAGAACAGATTTTAACGTTTTTACGACTCGAATAGTTAATGAC } \\
\text { ACTATTGTTGGAAA }\end{array}$ & $\begin{array}{l}\Delta \text { pilQ F2 (clean } \\
\text { deletion) }\end{array}$ \\
\hline CE88 & AGCGTATAACGATCAATTACTTCGC & $\Delta$ pilQ R2 \\
\hline BBC1891 & AATCACTTGAAGTGCAGATTCG & $\Delta$ comEA F1 \\
\hline BBC3451 & GTCGACGGATCCCCGGAATATGACGTATTGACATGAATTAACC & $\Delta$ comEA R1 \\
\hline BBC3452 & $\begin{array}{l}\text { GAAGCAGCTCCAGCCTACATAAGAGGCTGAGTCATGCTCAAAAT } \\
\text { AC }\end{array}$ & $\Delta$ comEA F2 \\
\hline BBC1894 & ATCTTCACCTTCTCCAAACTGG & $\Delta$ comEA R2 \\
\hline DOG0180 & AGTATTTGAGTTCGGGTATTATTGC & $\Delta$ comEC F1 \\
\hline DOG0181 & GTCGACGGATCCCCGGAATCATGGCAATGCCAGCAATC & $\Delta$ comEC R1 \\
\hline DOG0182 & GAAGCAGCTCCAGCCTACAAAGGGAGCGATTCATTTTAAGTTTG & $\Delta$ comEC F2 \\
\hline DOG0183 & TTACTCAAGCCGTTACAGTTCTG & $\Delta$ comEC R2 \\
\hline DOG0140 & GTTGCTGCATTTGTTCGATCTG & $\Delta$ comM F1 \\
\hline DOG0141 & $\begin{array}{l}\text { GTCGACGGATCCCCGGAATCATACTATTATTGTTCCATTATGGTG } \\
\text { c }\end{array}$ & $\Delta$ comM R1 \\
\hline DOG0142 & GAAGCAGCTCCAGCCTACATATCGCAGTGAACATAGCTAAAA & $\Delta \mathrm{comM} \mathrm{F2}$ \\
\hline DOG0143 & ATCAGTGGTTGGGAAGGTG & $\Delta \mathrm{comM} \mathrm{R2}$ \\
\hline CE23 & TTATGACTATCAATCTCAAGCACATGCT & $\begin{array}{l}\text { \pilB F1 or } \\
\text { 3XFLAG-pilB F1 }\end{array}$ \\
\hline CE93 & $\begin{array}{l}\text { ATTCACTGGTTACACGATTAATTTCCTGAAACTTAGGTGGTGTTG } \\
\text { TAAATGCTG }\end{array}$ & $\Delta$ pilB R1 \\
\hline
\end{tabular}




\begin{tabular}{|c|c|c|}
\hline CE94 & $\begin{array}{l}\text { CAGCATTTACAACACCACCTAAGTTTCAGGAAATTAATCGTGTAA } \\
\text { CCAGTGAAT }\end{array}$ & $\Delta$ pilB F2 \\
\hline CE26 & CTTTCATGGCGTGTTTGTCGTG & $\begin{array}{l}\Delta \text { pilB R2 or } \\
\text { 3XFLAG-pilB R2 }\end{array}$ \\
\hline CE210 & AAGCCAACCATAATCCGATTGTGAC & $\begin{array}{l}\Delta \text { tfpB F1 or tfpB- } \\
\text { 3XFLAG F1 }\end{array}$ \\
\hline CE328 & $\begin{array}{l}\text { TGGGACCACCCTTAAGACTTCTTCCCATTGTGTATCTATTTCAAA } \\
\text { ATGATATGTCAT }\end{array}$ & $\Delta$ tfpB R1 (in frame) \\
\hline CE329 & $\begin{array}{l}\text { ATGACATATCATTTTGAAATAGATACACAATGGGAAGAAGTCTTA } \\
\text { AGGGTGGTCCCA }\end{array}$ & $\Delta$ tfpB F2 (in frame) \\
\hline CE213 & CTCACGCCACCCAATCAAGAC & $\begin{array}{l}\Delta \text { tfpB R2 or tfpB- } \\
\text { 3XFLAG R2 }\end{array}$ \\
\hline CE240 & GTCGACGGATCCCCGGAATTTATTTCTCCCCCACACCATTCAC & $\begin{array}{l}\Delta \text { tfpB R1 (AbR } \\
\text { disruption) }\end{array}$ \\
\hline CE241 & $\begin{array}{l}\text { GAAGCAGCTCCAGCCTACATAAAAGGTTAGTTTAGATCTTAAGAT } \\
\text { TCACCTCAT }\end{array}$ & $\begin{array}{l}\Delta \text { tfpB F2 (AbR } \\
\text { disruption) }\end{array}$ \\
\hline DOG0130 & ССТСТССАСТСGTTTCTAAAGAAC & $\begin{array}{l}\Delta \text { cpiR or } \triangle \mathrm{cpiA} \text { or } \\
\text { cpiA-3X FLAG F1 or } \\
\text { cpiA-GFP F1 }\end{array}$ \\
\hline DOG0131 & GTCGACGGATCCCCGGAATCATAAGCCGATACTATCTGGATGG & $\Delta$ cpiR R1 \\
\hline DOG0132 & GAAGCAGCTCCAGCCTACAGAAGTTCAATGTCAGTTAAAACATC & $\Delta$ cpiR F2 \\
\hline DOG0133 & GACGTTGATTACGTAAATTTAATTCG & $\begin{array}{l}\Delta \text { cpiR or } \Delta \text { cpiA or } \\
\text { cpiA-3X FLAG R2 or } \\
\text { cpiA-GFP R2 }\end{array}$ \\
\hline BBC921 & $\begin{array}{l}\text { GTCGACGGATCCCCGGAATTTGATCACTTACTAATTTCATTATCA } \\
\text { TTTAAATG }\end{array}$ & $\Delta$ cpiA R1 \\
\hline BBC922 & GAAGCAGCTCCAGCCTACATAAAAAAGGACTGATTTCTCAGCCC & $\Delta$ cpiA F2 \\
\hline
\end{tabular}




\begin{tabular}{|c|c|c|}
\hline BBC2565 & TCCACCACTTCCACCTGCATTTTCATGAAACACTTGCTGC & cpiA-3X FLAG R1 \\
\hline BBC2570 & GCAGGTGGAGCAGGTGGATAAAAAAGGACTGATTTCTCAGCCC & cpiA-3X FLAG F2 \\
\hline BBC2272 & $\begin{array}{l}\text { GCAGGTGGAAGTGGTGGAGATTATAAAGACCATGATGGTGACTA } \\
\text { CAAGGATCACGACATTGATTATAAGGATGACGATGACAAAGCAG } \\
\text { GTGGAGCAGGTGGA }\end{array}$ & 3X FLAG MIDDLE F \\
\hline BBC2273 & $\begin{array}{l}\text { TCCACCTGCTCCACCTGCTTTGTCATCGTCATCCTTATAATCAAT } \\
\text { GTCGTGATCCTTGTAGTCACCATCATGGTCTTTATAATCTCCACC } \\
\text { АCTTCCACCTGC }\end{array}$ & 3X FLAG MIDDLE R \\
\hline DOG0229 & $\begin{array}{l}\text { CAATTTCACACAGGATCCCGGGAGGAGGTAACGTAATGATAATG } \\
\text { AAATTAGTAAGTGATCAAATTC }\end{array}$ & $\begin{array}{l}\text { Amplify cpiA for } \mathrm{P}_{t a c}- \\
\text { cpiA construct } \mathrm{F}\end{array}$ \\
\hline DOG0230 & TGTAGGCTGGAGCTGCTTCTTAATTTTCATGAAACACTTGCTGC & $\begin{array}{l}\text { Amplify cpiA for } \mathrm{P}_{t a c}- \\
\text { cpiA construct } \mathrm{R}\end{array}$ \\
\hline BBC3072 & $\begin{array}{l}\text { CACCATTATGATGGCAATCGTATGATTCGAAGTATGTGAAAAATC } \\
\text { TGC }\end{array}$ & $\begin{array}{l}\text { Amplify } P_{\text {cpiA }} \text { for } \\
P_{\text {cpiA-GFP F }}\end{array}$ \\
\hline BBC3074 & $\begin{array}{l}\text { CCCGGGATCCTGTGTGAAATTGACTAGCAGTATTGTATTACAAAA } \\
\text { СTTTTG }\end{array}$ & 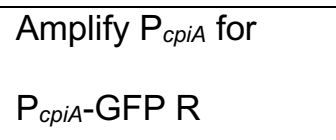 \\
\hline BBC3075 & $\begin{array}{l}\text { CAATTTCACACAGGATCCCGGGAGGAGGTCGGCTTATGGATATA } \\
\text { GGTCGC }\end{array}$ & $\begin{array}{l}\text { Amplify cpiR for } \\
\text { PBAD-cpiR construct } \\
\text { F }\end{array}$ \\
\hline BBC2560 & $\begin{array}{l}\text { TGTAGGCTGGAGCTGCTTCTTACTTTTTAGTGTCTATCAAAGTAA } \\
\text { AAATGAGATG }\end{array}$ & $\begin{array}{l}\text { Amplify cpiR for } \\
\text { PBAD-cpiR construct } \\
\text { R }\end{array}$ \\
\hline CE383 & GAAAAATTTGTTGAGCAGTTGAATGATGG & pilMF1 \\
\hline CE1507 & GTCGACGGATCCCCGGAATCTTCTTTGGCCTACGATATAACCTG & $\begin{array}{l}\triangle \text { pilMR1 (AbR } \\
\text { disruption) }\end{array}$ \\
\hline CE1508 & $\begin{array}{l}\text { GAAGCAGCTCCAGCCTACACGAATAGTTAATGACACTATTGTTG } \\
\text { GAAA }\end{array}$ & $\begin{array}{l}\Delta \text { pilQF2 (AbR } \\
\text { disruption) }\end{array}$ \\
\hline
\end{tabular}




\begin{tabular}{|l|l|l|}
\hline BBC2565 & tccaccacttccacctgcATTTTCATGAAACACTTGCTGC & cpiA-GFP R1 \\
\hline BBC2570 & gcaggtggagcaggtggaTAAAAAAGGACTGATTTCTCAGCCC & cpiA-GFP F2 \\
\hline BBC279 & gcaggtggaagtggtggaCGTAAAGGAGAAGAACTTTTC & $\begin{array}{l}\text { Amplify GFP for } \\
\text { fusions F }\end{array}$ \\
\hline BBC350 & tccacctgctccacctgcGTTGTATAGTTCATCCATGCC & $\begin{array}{l}\text { Amplify GFP for } \\
\text { fusions R }\end{array}$ \\
\hline BBC3303 & tccaccacttccacctgcCATTAGACCGCCTTGTGATTCTG & 3 XFLAG-pilB R1 \\
\hline BBC3304 & $\underline{\text { gcaggtggagcaggtggaTCAGCATTTACAACACCACC }}$ & 3XFLAG-pilB F2 \\
\hline BBC3751 & $\underline{\text { tccaccacttccacctgcAGTTAATGGGACCACCCTTAAGAC }}$ & tfpB-3XFLAG R1 \\
\hline BBC3752 & $\underline{\text { gcaggtggagcaggtggaTAGTAAAAGGTTAGTTTAGATCTTAAGATTCA }}$ & tfpB-3XFLAG F2 \\
\hline
\end{tabular}

